Volnei Garrafa ${ }^{1}$

Karla Amorim ${ }^{2}$

Ticiana Garcia ${ }^{1}$

Camilo Manchola ${ }^{1}$

\title{
BIOÉTICA E VIGILÂNCIA SANITÁRIA
}

Sanitary surveillance and bioethics

${ }^{1}$ Universidade de Brasília. Brasília/DF, Brasil.

${ }^{2}$ Universidade Federal do Rio Grande do Norte. Natal/RN, Brasil.

Correspondência: Volnei Garrafa. E-mail: garrafavolnei@gmail.com.

Recebido: 04/07/2016. Revisado: 28/10/2016. Aprovado: 04/11/2016. 


\section{RESUMO}

As práticas regulatórias no campo da vigilância sanitária são indispensáveis. O objetivo deste estudo é mostrar, tomando como referência a Agência Nacional de Vigilância Sanitária, organismo referencial da vigilância sanitária no Brasil, que a bioética oferece aos organismos públicos uma série de ferramentas teóricas do campo da ética aplicada para o bom exercício e controle dessas práticas. Nesse intuito, o trabalho utiliza duas referências da bioética para o desenvolvimento de uma análise comparativa e de apoio às atividades regulatórias no campo da vigilância sanitária: a Declaração Universal sobre Bioética e Direitos Humanos da Unesco e a teoria da bioética de intervenção. Conclui-se que organismos e técnicos que trabalham com atividades de regulação podem aproveitar, em seu exercício profissional, os princípios e referenciais propostos pela bioética, especialmente aqueles relacionados à Declaração e à teoria de bioética da intervenção, esta última configurada pela observação e utilização dos princípios da prudência, precaução, proteção e prevenção.

\section{Palavras-Chave}

Bioética; Intervenção; Regulação; Saúde Pública; Vigilância Sanitária.

\section{ABSTRACT}

Regulatory practices in the field of health surveillance are indispensable. The aim of this study is to show - taking the Brazilian National Surveillance Agency, governing body of sanitary surveillance in Brazil as a reference - that bioethics provides public bodies a series of theoretical tools from the field of applied ethics for the proper exercise and control of these practices. To that end, the work uses two references of bioethics for the development of a comparative and supportive analysis to regulatory activities in the field of health surveillance: the Universal Declaration on Bioethics and Human Rights of Unesco and the theory of intervention bioethics. We conclude that organizations and staff working with regulatory activities can take advantage of the principles and frameworks proposed by bioethics, especially those related to the Declaration and the theory of intervention bioethics, the latter being set by the observation and use of the principles of prudence, precaution, protection and prevention.

\section{Keywords}

Bioethics; Health Surveillance; Intervention; Public Health Regulation. 


\section{Introdução}

Nos seus 45 anos de existência, a bioética recebeu variadas interpretações conceituais provenientes de diferentes estudiosos do assunto: uma nova ciência, para Potter $^{1}$; uma disciplina, para Reich ${ }^{2}$; um território do conhecimento científico, para Bellino $^{3}$; ou mesmo um verdadeiro movimento cultural, nos moldes do movimento ambiental dos anos 1960, para Mori ${ }^{4}$.

Concretamente, ela surgiu no início dos anos 1970 como uma resposta teórica e aplicada a dois tipos diferentes de abusos historicamente constatados após o término da Segunda Guerra Mundial. O primeiro deles é relacionado ao acelerado e pouco controlado desenvolvimento científico e tecnológico constatado na época, que avançou desde a descoberta e utilização da energia atômica (para o bem e para o mal) até a recente utilização terapêutica de células tronco-embrionárias, passando pelas pesquisas com organismos e plantas geneticamente modificados, pelos ataques ao meio ambiente a ao ecossistema terrestre e planetário, pelas novas tecnologias reprodutivas, pelos transplantes de órgãos e tecidos humanos etc.

O segundo diz respeito aos reincidentes abusos constatados em pesquisas clínicas desenvolvidas principalmente nos Estados Unidos da América do Norte (EUA) - mesmo após o Tribunal de Nuremberg, que julgou os abusos cometidos pelos médicos nazistas nos campos de concentração - e que levaram o país a criar a Comissão para a Proteção de Sujeitos Humanos de Pesquisas Médicas e Comportamentais. Esse trabalho, pela importância e repercussão internacional de suas propostas, ficou internacionalmente conhecido como Belmont Report $t^{5}$, em referência à cidade onde as reuniões foram realizadas, e deu origem a uma nova e sólida base para regulação e controle ético das pesquisas envolvendo seres humanos a partir de então naquele país.

\section{Bioética: breve histórico, dos primórdios aos dias atuais}

Embora tenham surgido no mesmo lugar (EUA) e em momentos próximos, as respostas epistemológicas e de abordagem prática da bioética aos dois problemas apontados - o acelerado e pouco controlado desenvolvimento científico e tecnológico e reincidentes abusos em pesquisas clínicas - tomaram percursos diversos. A primeira linha relacionada com o tema e defendida por Potter ${ }^{6}$ - um eminente cancerologista básico

\footnotetext{
${ }^{1}$ POTTER, Van Rensselaer. Bioethics: a bridge to the future. New Jersey: Prentice-Hall, 1971.

${ }^{2} \mathrm{REICH}$, Warren Thomas. Encyclopedia of Bioethics. $2^{\text {nd }}$ ed. New York: Macmillan Press; 1995.

${ }^{3}$ BELLINO, Francesco. Fundamentos de bioética: aspectos antropológicos, ontológicos e morais. Bauru: EDUSC, 1991.

${ }^{4}$ MORI, Maurizio. A bioética: sua natureza e história. Humanidades (UnB), Brasília, v. 9, n. 4, p. 332-341, 1994. ${ }^{5}$ UNITED STATES OF AMERICA. Department of Health, Education, and Welfare. Belmont Report. Disponível em: <http://www.hhs.gov/ohrp/humansubjects/guidance/belmont.html>. Acesso em: 22 nov. 2013.

${ }^{6}$ POTTER, Van Rensselaer. Bioethics, the science of survival. Perspectives in Biology and Medicine, New York, v. 14 , p. $127-153,1970$.
} 
que presidiu durante muitos anos o National Cancer Institute - entendeu a bioética a partir de um enfoque conceitualmente macro, comprometida com a própria preservação e sobrevivência futura do planeta. A segunda, desenvolvida pelo ginecologista-obstetra Andre Hellegers no Kennedy Institute da Universidade de Georgetown, enfocou diretamente o campo das ciências biomédicas, direcionando a bioética preferencialmente às relações dos profissionais de saúde com seus pacientes, e dos pesquisadores e patrocinadores de pesquisas clínicas com os sujeitos das mesmas. Esta última versão, que reduziu a interpretação da bioética quase que exclusivamente ao campo biomédico e biotecnológico, foi a que alcançou popularidade no mundo todo a partir dos anos 1980 e 1990, fundamentada em quatro princípios presumivelmente universais derivados do Relatório de Belmont: respeito pela autonomia, não maleficência, beneficência e justiça ${ }^{7}$.

A aceitação quase que hegemônica dessa proposta - chamada criticamente de "principialismo" por estar assentada exclusivamente nos quatro princípios acima citados - passou a ser contestada por filósofos e bioeticistas já nos anos 1990. As críticas tiveram a ver especificamente com: a fundamentação epistemológica da proposta, pautada em posições filosóficas conflitantes como o utilitarismo, a ética das virtudes e a deontologia; sua pretensão de ser aplicável universalmente, relativa à defesa da existência de uma moral única, universal no mundo; e a maximização de um dos princípios (a autonomia) sobre os outros.

Esse panorama crítico influenciou muito a implantação de um novo rumo para a bioética, dado em 2005 - quando, depois de dois anos de intensas discussões, a Organização das Nações Unidas para a Educação, Ciência e Cultura (Unesco), com o apoio unânime de 191 países, homologou o mais importante documento internacionalmente produzido com relação ao assunto: a Declaração Universal sobre Bioética e Direitos Humanos ${ }^{8}$ (DUBDH).

Essa Declaração mudou substancialmente a fundamentação e o direcionamento teórico-prático da bioética, ampliando sua agenda de trabalho e ação dos temas preferencialmente biomédicos e biotecnológicos aos quais vinha se dedicando (apesar das críticas provenientes de diferentes países, entre eles o Brasil) para os campos sanitário (direito à saúde e medicamentos, acesso à nutrição adequada etc.), social (eliminação da marginalização e da exclusão, redução da pobreza e do analfabetismo etc.) e ambiental (proteção do meio ambiente, da biosfera e da biodiversidade) ${ }^{9}$.

${ }^{7}$ BEAUCHAMP, Tom; CHILDRESS James. Principles of biomedical ethics. $1^{\text {st }}$. ed. New York; Oxford: Oxford University Press, 1979. BEAUCHAMP, Tom; CHILDRESS James. Principles of biomedical ethics. $7^{\text {nd }}$. ed. New York; Oxford: Oxford University Press, 2013.

¿UNESCO. Declaração Universal sobre Bioética e Direitos Humanos. Paris, 2005. Tradução brasileira sob a responsabilidade da Cátedra Unesco de Bioética da Universidade de Brasília. Disponível em: <Disponível em: www.bioetica.catedraunesco.unb.br>. Acesso em: 22 set. 2015.

${ }^{9}$ GARRAFA, Volnei. De uma bioética de princípios a uma bioética interventiva. Revista Bioética CFM, v. 13, n. 1, p. 125-134, 2005. Disponível em: <http://revistabioetica.cfm.org.br/index.php/revista_bioetica/article/ view/97/102>. GARRAFA, Volnei. O novo conceito de bioética. In: GARRAFA, Volnei; KOTTOW, Miguel; SAADA, Alya (Orgs.). Bases conceituais da bioética: enfoque latino-americano. São Paulo: Ed. Global; UNESCO. 2006. p. 9-15. 
A DUBDH, da qual o Brasil é um dos signatários, ampliou a agenda bioética internacional estendendo sua fundamentação teórico-prática para 15 princípios que, além de incorporar os quatro anteriores - que passaram a ter outras denominações (benefício e dano; autonomia e responsabilidade individual; consentimento; indivíduos sem a capacidade para consentir) -, incluíram novos temas, como: dignidade humana e direitos humanos; respeito pela vulnerabilidade humana e pela integridade individual; privacidade e confidencialidade; igualdade, justiça e equidade; não discriminação e não estigmatização; respeito pela diversidade cultural e pelo pluralismo; solidariedade e cooperação; responsabilidade social e saúde; compartilhamento de benefícios; proteção das gerações futuras; e proteção do meio ambiente, da biosfera e da biodiversidade.

Em resumo, a bioética, que nasceu entre interpretações e aplicações diversas, a partir da referida Declaração assumiu um caráter, além de academicamente mais bem definido e ampliado, também politizado, mais interventivo e crítico ${ }^{10}$. E é nesse sentido que passaremos a discutir a relação da bioética - essa "nova" bioética redefinida e redesenhada pela Unesco - com o tema da regulação no campo da vigilância sanitária.

É indispensável registrar, ainda, o fato de a DUBDH enfatizar que sua elaboração é: “[...] dirigida aos Estados. Quando apropriado e pertinente, ela também oferece orientação para decisões ou práticas de indivíduos, grupos, comunidades, instituições e empresas públicas e privadas ${ }^{11}$ " (artigo 1, item b). Isso significa que, sendo o Brasil signatário desse documento e sua Agência Nacional de Vigilância Sanitária (Anvisa) a empresa pública vinculada ao Ministério da Saúde incumbida do controle sanitário nos campos dos medicamentos, cosméticos, produtos para a saúde (incluindo alimentos) e serviços de saúde, suas normas - chamadas de não vinculantes no campo do direito internacional - podem e devem ser seguidas, legitimando ações regulatórias e interventivas quando pertinente e/ou necessário.

\section{Regulação e bioética}

A Anvisa, órgão reitor da vigilância sanitária no Brasil e referência do tema para este artigo, entende a regulação, entre outros aspectos, como um modo de intervenção do Estado para impedir possíveis danos ou riscos à saúde da população. Segundo a Agência, esse processo funciona por meio de regulamentação, controle e fiscalização das relações de produção e consumo de bens e serviços relacionados à saúde $^{12}$. De acordo com esta definição, é possível relacionar direta ou indiretamente

\footnotetext{
${ }^{10}$ GARRAFA, Volnei. Ampliação e politização do conceito internacional de bioética. Revista Bioética, v. 20, n. 1, p. 9-20, 2012. Disponível em: <http://revistabioetica.cfm.org.br/index.php/revista_bioetica/article/ view/711/731>

${ }^{11}$ UNESCO. Declaração Universal sobre Bioética e Direitos Humanos, cit.

${ }^{12}$ AGÊNCIA NACIONAL DE VIGILÂNCIA SANITÁRIA. Regulação sanitária. Disponível em: <portal.anvisa.gov.br/ wps/portal/anvisa/ANVISA/regulacaosanitaria>. Acesso em: 26 set. 2013.
} 
o tema da regulação com a maioria dos 28 artigos que compõem a Declaração da Unesco. Embora no transcurso do trabalho vários artigos da DUBDH venham a serem utilizados, o primeiro dos dois referenciais mencionados e que dá sustentação ao presente tópico discutirá especificamente dois desses artigos, por estarem mais próximos ao assunto em estudo, a saber: o artigo 4 - Benefício e Dano; e o artigo 20 - Avaliação e Gerenciamento de Riscos.

Esses artigos dizem respectivamente o seguinte:

Artigo 4 - Os benefícios diretos e indiretos a pacientes, sujeitos de pesquisa e outros indivíduos afetados devem ser maximizados, e qualquer dano possível a tais indivíduos deve ser minimizado, quando se trate da aplicação e do avanço do conhecimento científico, das práticas médicas e tecnologias associadas.

[...]

Artigo 20 - Devem-se promover a avaliação e o gerenciamento adequado de riscos com relação à medicina, às ciências da vida $\mathrm{e}$ às tecnologias associadas ${ }^{13}$.

Tanto a definição proposta pela Anvisa como o conteúdo dos dois citados artigos da Declaração estão de acordo com afirmação de Bufler e Kyle ${ }^{14}$ no sentido de que é função do Estado moderno, por meio de seus poderes legislativo e normativo, regular e monitorar os possíveis efeitos adversos de um vasto e complexo conjunto de exposições natural ou artificialmente criadas (medicamentos, vacinas, equipamentos etc.) ou que podem interferir na saúde das pessoas ou coletividades (qualidade da água e dos alimentos, exposição ambiental a poluentes etc.). Segundo Barreto ${ }^{15}$, cabe ao Estado definir questões tão diversas como: (a) autorizar o uso de cada medicamento ou vacina, os parâmetros de teste que garantam sua segurança e eficácia, os padrões de sua produção etc.; (b) definir níveis máximos aceitáveis para diferentes tipos de poluentes, aditivos alimentares, inseticidas, radiações etc.; (c) determinar parâmetros para uma extensa série de equipamentos e tecnologias usada pelo sistema de saúde; e (d) criar parâmetros e meios para o monitoramento dos efeitos adversos de toda a imensa gama de recursos tecnológicos utilizada pelo sistema de saúde.

O objetivo do presente estudo teórico-discursivo é apresentar e discutir alguns princípios e referenciais utilizados no contexto da bioética, de modo a contribuir com novas ferramentas e possibilidades metodológicas para o exercício das ações reguladoras públicas no campo da saúde.

\footnotetext{
${ }^{13}$ UNESCO. Declaração Universal sobre Bioética e Direitos Humanos, cit.

${ }^{14}$ BUFLER, Patricia; KYLE, Amy. Regulatory reform proposals and public health. Environ. Health Perspect, v. 104, n. 4, p. 356-361, 1996. Disponível em: <https://www.ncbi.nlm.nih.gov/pmc/articles/PMC1469327/>.

${ }^{15}$ BARRETO, Mauricio. O conhecimento científico e tecnológico como evidência para políticas e atividades regulatórias em saúde. In: COSTA, Edina Alves (Org.). Vigilância sanitária: desvendando o enigma. Salvador: Edufba. 2008. p. 91-106.
} 
Pelo acelerado desenvolvimento científico e tecnológico hoje constatado, é necessário que tenhamos um considerável número de normas regulatórias que controlem o uso comercial seguro de novos produtos ou técnicas propostos ao mercado. E mais necessário ainda é que o Estado crie os organismos públicos responsáveis pela execução dessas ações, como é o caso da Anvisa com relação ao setor da vigilância no campo da saúde pública e coletiva. Contudo, para que as tarefas delegadas a esses organismos sejam correta, efetiva e competentemente executadas, além da indispensável capacitação profissional exigida dos atores/ técnicos nelas envolvidas, estes necessitam ter, igualmente, adequada formação ética (prática, aplicada) para garantir ao Estado segurança em suas tomadas de decisão, principalmente frente a situações de indefinição e/ou conflitos. Nesse sentido, Abraham e Lewis ${ }^{16}$ chegam a afirmar que as questões regulatórias em saúde, por interferirem no cotidiano das pessoas, estão relacionadas com o próprio conceito de cidadania, como já vem sendo observado em diversas sociedades ocidentais modernas.

As funções e os papéis dos organismos públicos reguladores são de grande complexidade. Sem se tornarem obstáculo para os avanços e aplicações da ciência e tecnologia, como, então, equilibrar os benefícios (individuais e coletivos) advindos de sua liberação e uso, mesmo diante de possíveis danos, embora menores, mas muitas vezes inevitáveis? Por outro lado, é indispensável que um país soberano como o Brasil esteja capacitado tecnicamente para impedir a incorporação passiva de modelos, métodos e mesmo ferramentas internacionais que não tenham aplicação adequada ao contexto e aos interesses nacionais. Ao mesmo tempo, é importante também assinalar a necessidade de independência com relação às propostas de harmonização internacional de normas que forem definidas unilateralmente por alguns poucos países e pautadas por evidentes interesses grupais.

É dentro desse contexto que o artigo 4 da DUBDH tenta propor normas de atuação, de modo não vinculante. É necessário registrar que tais normas não têm poder legislativo por serem originárias de um organismo internacional que apenas sugere políticas e propostas normativas de atuação. De qualquer forma, ao ler o referido artigo, temos a impressão de estarmos diante de uma afirmação ética de cunho utilitarista, uma vez que ele trata de maximizar os benefícios e minimizar os danos. De fato, a decisão de beneficiar o maior número de pessoas pelo maior espaço de tempo possível, com ações resultando nos melhores benefícios coletivos, é uma afirmação utilitarista e consequencialista advinda das ideias dos filósofos Jeremy Bentham e John Stuart Mill - escritas nos séculos XVII e XVIII, respectivamente -, mas que foram incorporadas inclusive na fundamentação teórica da Bioética de Intervenção, a qual será abordada mais adiante.

\footnotetext{
${ }^{16}$ ABRAHAM, John; LEWIS, Graham. Citizenship, medical expertise and the capitalist regulatory state in Europe. Sociol., v. 36, n. 1, p. 67-88, 2002.
} 
Contudo, segundo Paranhos, Melo e Garrafa ${ }^{17}$, seria um erro considerar que a maximização de benefícios e a minimização de danos caberiam somente aos utilitaristas, uma vez que a conhecida filosofia não consequencialista de Kant também pode ser utilizada para a defesa dos pacientes e usuários, particularmente a partir de um de seus mais conhecidos imperativos categóricos: "Age de tal maneira que uses a humanidade, tanto na tua pessoa, como na pessoa de qualquer outro, sempre e simultaneamente como fim e nunca simplesmente como meio"18.

A obrigação moral para com os outros (no caso específico da regulação, essa "obrigação" refere-se aos organismos e ao pessoal técnico que emitem normas e pareceres) é levada ao extremo por alguns autores, como Lévinas ${ }^{19}$ - que afirma que somos responsáveis pelo outro sem esperar reciprocidade; segundo ele, a reciprocidade (ou não) fica por conta do outro. Essa interpretação baseia-se na fundamentação filosófica proposta por Heidegger ${ }^{20}$, de acordo com quem uma das características do ser é "ser-no-mundo" como "ser-com"; ou seja, não somos "simplesmente", mas "somos-com-os-outros" e, assim, desenvolvemos forçosamente uma peculiaridade essencial: o cuidado. Com base em Heidegger, o pensador brasileiro Leonardo Boff ${ }^{21}$ expressou com relação à "ética do cuidado" que, sendo o ser humano um ser essencialmente cuidado, deve também ter cuidado pelo outro.

A essência da questão regulatória na óptica da bioética, portanto, não incide exclusivamente na liberação (ou não) do uso de novos medicamentos, alimentos, cosméticos, materiais ou tecnologias, mas essencialmente no devido controle responsável das novidades. Toda a questão passa também pela adequada avaliação e pelo competente gerenciamento dos possíveis riscos envolvidos no assunto que está sendo analisado, de acordo com o artigo 20 da DUBDH. E o controle desse processo, para ser completo e seguro, deve se dar obrigatoriamente - além dos planos científico e tecnológico - também no plano ético, recordando que "a ética sobrevive sem a ciência e a técnica; sua existência não depende delas; a ciência e a técnica, contudo, não podem prescindir da ética, sob risco de se transformarem em mecanismos iatrogênicos e muitas vezes desastrosos para pessoas, comunidades e mesmo países"22. Nesse sentido:

\footnotetext{
${ }^{17}$ PARANHOS, Flávio Rocha Lima; MELO, Rosana Leite; GARRAFA, Volnei. Estudo crítico do Princípio de Benefício e Dano. Revista Bioética, v. 23, n. 1, p. 12-19, 2015. Disponível em: <http://www.scielo.br/pdf/ bioet/v23n1/1983-8034-bioet-23-1-0012.pdf>.

${ }^{18} \mathrm{KANT}$, Immanuel. Fundamentação da metafísica dos costumes. Tradução Paulo Quintela. Lisboa: Edições 70, 1997. p. 69.

${ }^{19}$ LÉVINAS, Emmanuel. Éthique et infini. Fayar France Culture. 1984. p. 94-5.

${ }^{20}$ HEIDEGGER, Martin. Being-in-the world as being-with and being a self: the they. In: HEIDEGGER, Martin. Being and time. Translated Joan Stambaugh. New York: State University of New York Press. 1996. p. 107-122. (SUNY series in contemporary continental philosophy).

${ }^{21}$ BOFF, Leonardo. Saber cuidar: ética do humano - compaixão pela terra. 6. ed. Petrópolis: Vozes, 2000.

${ }^{22}$ GARRAFA, Volnei. Bioética e manipulação da vida. In: NOVAES, Adauto (Org.). O homem-máquina - a ciência manipula o corpo. São Paulo: Companhia das Letras. 2003. p. 213-225.
} 
O “xis" da questão está no fato de que, dentro de uma escala hipotética de valores vitais para a humanidade, a ética ocupa posição diferenciada em comparação com a pura ciência e a pura técnica. Nem anterior, nem superior, mas simplesmente diferenciada. Além de sua importância qualitativa no caso, a ética serve como instrumento preventivo e prudencial contra abusos atuais e futuros que venham trazer lucros exagerados para poucos, em detrimento do alijamento e sofrimento da maioria da sociedade e do próprio desequilíbrio planetário ${ }^{23}$.

\section{A bioética de intervenção e os "Quatro Pês" para uma prática regulatória responsável}

O segundo referencial utilizado para a discussão do presente artigo é a chamada bioética de intervenção (BI). Algumas ações de vigilância sanitária partem, como já foi dito, da prerrogativa legal do poder de regulação e controle da agência pública responsável. Ao executar tais ações, no entanto, esse organismo deve levar em consideração o uso de referenciais éticos que proporcionem a devida sustentação às mesmas. Nesse sentido, torna-se apropriada a utilização da BI, corrente de pensamento genuinamente brasileira e latino-americana, construída no final dos anos 1990 como uma perspectiva antihegemônica às teorias bioéticas tradicionais vindas do Hemisfério Norte e sustentadas nos quatro princípios já mencionados e de fundamentação moral nortista anglo-saxônica. Alguns anos após sua criação e seu reconhecimento, a BI acabou vendo incorporados ao contexto internacional grande parte dos princípios e referenciais que já vinha utilizando, os quais se aproximam de outra vertente teórica latino-americana - a bioética de proteção ${ }^{24}$ - sendo que ambas diferem claramente do principialismo, a corrente internacional mais difundida globalmente no campo da bioética e já apresentada anteriormente.

A BI é considerada uma "epistemologia do hemisfério sul do planeta", partindo da ótica de defesa da "banda mais vulnerável da sociedade" e considerando, entre outros aspectos, que as tomadas de decisão públicas e coletivas mais justas e moralmente justificadas são aquelas - de posição utilitarista e consequencialista, além de complementarmente solidária - que privilegiam o maior número de pessoas, pelo maior espaço de tempo, e que resultem nas melhores consequências coletivas. No campo privado e individual, advoga pela busca de soluções viáveis e práticas para os conflitos, contextualizando-os caso a caso $^{25}$, com a utilização do princípio da solidariedade crítica, entre outros referenciais ${ }^{26}$.

\footnotetext{
${ }^{23}$ GARRAFA, Volnei. Transgênicos, ética e controle social. O Mundo da Saúde, v. 23, n. 5, p. 286-289, 1999.

${ }^{24}$ SCHRAMM, Fermin Roland; KOTTOW, Miguel. Principios bioéticos en salud pública: limitaciones y propuestas. Cad. Saúde Pública, v. 17, p. 949-956, 2001. Disponível em: <http://www.scielo.br/pdf/csp/ v17n4/5301.pdf>. http://dx.doi.org/10.1590/S0102-311X2001000400029.

${ }^{25}$ GARRAFA, Volnei; PORTO, Dora. Intervention bioethics: a proposal for peripheral countries in a context of power and injustice. Bioethics, v. 17, n. 5-6, p. 399-416, 2003. 10.1111/1467-8519.00356.

${ }^{26}$ NASCIMENTO Wanderson Flor, GARRAFA, Volnei. Por uma vida não colonizada: diálogo entre Bioética de Intervenção e Colonialidade. Saúde Soc São Paulo, v. 20, n. 2, p. 287-299, 2011. Disponível em: <http://www.revistas.usp.br/sausoc/article/view/29791/31673>.
} 
Dentre as diversas ferramentas teóricas e metodológicas de sustentação à BI, estão os chamados "Quatro Pês" para o exercício de práticas éticas públicas responsáveis: prudência, precaução, proteção e prevenção. Todas estas quatro categorias já fazem parte do arsenal de atuação da vigilância sanitária nos mais diferentes cenários que se apresentam para serem solucionados. Tais referenciais, contudo, se utilizados com o devido rigor e precisão, podem adquirir uma utilidade extraordinária diante de necessárias tomadas de decisão frente à liberação e utilização de novas tecnologias de serviços e produtos para a saúde.

Se, por um lado, a prudência e a precaução são categorias disponíveis de serem usadas diante do desconhecimento dos novos insumos sanitários, a proteção e a prevenção são referências utilizadas para evitar possíveis danos e iatrogenias advindos do uso desses produtos, uma vez que a população que eventualmente necessita deles é também vulnerável e suscetível aos possíveis riscos associados. Para complementar a reflexão, é apresentado um breve resumo de cada um dos "Quatro Pês" a fim de ampliar a proposta já formulada por Leite et al. ${ }^{27}$, aplicando-os ao presente estudo e relacionando-os à DUBDH.

\subsection{Prudência}

A prudência, que na Antiguidade era vista como uma das quatro virtudes cardeais juntamente com a justiça, a coragem e a temperança, hoje em dia tem seu significado transferido para o campo do cuidado, da cautela e do risco. Gracián ${ }^{28}$ entende que a prudência é composta, entre outros atributos, por: conhecimento, discernimento, sabedoria, inteligência, razão, reflexão, ponderação, percepção, decisão, benevolência, beneficência, condescendência e sensatez.

Tanto Aristóteles quanto São Tomás de Aquino e Santo Agostinho discorreram sobre a prudência, uma vez que na Antiguidade ela era parte central das discussões sobre as virtudes que deviam ser cultivadas nos seres humanos. Aristóteles, assim como os gregos, entendia a prudência como phronésis - uma virtude intelectual, tendo em vista sua ligação com a verdade, o conhecimento e a razão. Era então um saber-fazer que pressupunha estar sempre atento e se relacionava com outras virtudes, como a paciência e a antecipação. A prudência, nessa perspectiva, orienta as escolhas e o que se deve resguardar, tendo relação com boas deliberações e diretamente ligada à inteligência ${ }^{29}$.

Quanto a Santo Agostinho e São Tomás de Aquino, o primeiro dizia que a prudência é uma forma de amor que se escolhe com sagacidade ou sabedoria. Já

\footnotetext{
${ }^{27}$ LEITE, Denise Ferreira; BARBOSA, Patrícia Fernanda Toledo; GARRAFA, Volnei. Auto-hemoterapia, intervenção do Estado e Bioética. Rev Assoc Médica Brasileira, v. 54, n. 2, p. 183-188, mar./abr. 2008. Disponível em: <http:// www.scielo.br/pdf/ramb/v54n2/a26v54n2.pdf>. http://dx.doi.org/10.1590/S0104-42302008000200026. ${ }^{28}$ GRACIÁN, Baltasar. A arte da prudência. São Paulo: Martin Claret, 2006. p. 151.

${ }^{29}$ MARQUES, Ramiro. A prudência em Aristóteles. Disponível em: <http://www.eses.pt/usr/ramiro/docs/etica_ pedagogia/a\%20prud\%C3\%AAncia\%20em\%20arist\%C3\%B3teles\%5B1\%5D.pdf>. Acesso em: 22 jun. 2016.
} 
Tomás de Aquino ${ }^{30}$ a definia como relativa ao ato de decidir, uma vez que o bem deliberar faz parte subjetiva do espectro da prudência e se relaciona com o juízo reto para a tomada de decisão frente a ações particulares, guardando aproximação com a perspicácia nos julgamentos; no sentido contrário da prudência está a imprudência, entendida como a falta da primeira.

Assim, prudência é tida como a mãe e guia das demais virtudes, observando-se que ao prudente não cabem ações intempestivas, inoportunas, irracionais ou súbitas. A prudência coloca sua atenção na preparação dos fatos e eventos, e nunca na precipitação nem no amadorismo ou na improvisação.

$\mathrm{Na}$ contemporaneidade, têm se desenvolvido vários conceitos que estão na mesma linha da imprudência: a negligência (falta de solicitude devida); a precipitação ou a temeridade (falta de deliberação); a inconsideração (falta de julgamento); e a inconstância (abandono de um bom propósito determinado). Nesse sentido, a prudência teria relação com o artigo 20 da DUBDH, relativo à avaliação e gestão do risco.

$\mathrm{Na}$ área sanitária, hoje em dia, fala-se muito em imprudência quando da ocorrência de erro médico, científico ou da vigilância. Também nessa mesma linha, é conveniente mencionar as três modalidades da culpa em termos legais, uma vez que elas guardam relação com a imprudência, negligência ou imperícia. O artigo 18, inciso II, do Código Penal Brasileiro (CPB) aduz que comete crime culposo o agente que deu causa ao resultado por imprudência, negligência ou imperícia ${ }^{31}$, fazendo referência expressa aos eventos que possam acontecer, por exemplo, como resultado da inoperância de agentes ou instituições, dentre as quais as de vigilância sanitária.

\subsection{Precaução}

O respeito à precaução é interpretado como a adoção de medidas protetoras relativas a possíveis danos ou riscos que poderiam ser produzidos por determinados produtos ou tecnologias. As ferramentas jurídicas supranacionais têm sido pioneiras na definição da precaução, principalmente a partir de noções relacionadas ao meio ambiente, com elementos relativos à prevenção das ameaças e de responsabilidade. Nessa linha de ideias, seu propósito precípuo é a proteção da humanidade e do meio ambiente contra possíveis ameaças dos atos humanos.

Para Andorno ${ }^{32}$, a precaução pode ser mais bem entendida se revista à luz da prudência, uma vez que esta última lhe confere um marco de referência útil, relativo

\footnotetext{
${ }^{30}$ AQUINO, Tomás. Suma teológica V - A fé. A esperança. A caridade. A prudência. II Seção da II Parte, Questões 1-56. São Paulo: Edições Loyola; 2004. p. 682.

${ }^{31}$ BRASIL. Código Penal brasileiro. São Paulo: Saraiva, 2002. p. 509.

${ }^{32}$ ANDORNO, Roberto. The precautionary principle: a new legal standard for a technological age. Journal of International Biotechnology, v. 1, n. 1, p. 11-19, 2005. https://doi.org/10.1515/jibl.2004.1.1.11.
} 
a uma aproximação mais cuidadosa de tecnologias que poderiam ser potencialmente perigosas, por exemplo. Esse aspecto é essencial ao se falar de regulamentação, controle e fiscalização das relações de produção e consumo de bens e serviços relacionados à saúde - missão central da Anvisa, por exemplo -, uma vez que uma abordagem da precaução a partir da prudência pode assegurar menores danos e maiores benefícios.

De fato, não é incomum na área da saúde que expressões como "riscos potenciais ou reais", "avanços tecnológicos" e "medidas de antecipação" despertem uma atenção imediata. Desta feita, o que busca a precaução é uma salvaguarda antecipatória, ainda que não haja risco, mas apenas sua iminência, e também quando não puder ser afastada a certeza científica absoluta da não ocorrência do dano ${ }^{33}$.

A Comissão sobre Ética do Desenvolvimento Científico e Tecnológico da Unesco (Comest) ${ }^{34}$ concorda com isso, uma vez que considera que a aplicação da precaução ocorre em circunstâncias relacionadas à inexistência de certezas científicas sobre a origem, gravidade, possibilidade e tipo do dano; à presença de suposições ou arquétipos, fundamentados em evidências científicas, do possível dano; à diminuição impraticável das dúvidas sem um acréscimo na ausência de conhecimento de outros fatores importantes; ao dano potencial grave, não reversível ou eticamente inadmissível à geração atual ou futura; e à obrigação de atuação imediata, pois uma ação tardia envolveria maior dificuldade ou custo.

A propósito das declarações internacionais, é importante ressaltar também a Conferência das Nações Unidas sobre o Meio Ambiente e o Desenvolvimento de 1992, que produziu a Declaração do Rio sobre Meio Ambiente e Desenvolvimento - a qual refere internacionalmente pela primeira vez a precaução como princípio:

Princípio 15 - Com o fim de proteger o meio ambiente, o princípio da precaução deverá ser amplamente observado pelos Estados, de acordo com suas capacidades. Quando houver ameaça de danos graves ou irreversíveis, a ausência de certeza científica absoluta não será utilizada como razão para o adiamento de medidas economicamente viáveis para prevenir a degradação ambiental ${ }^{35}$.

Atualmente, e apesar de sua aplicação primeira ter sido no tema ambiental, percebe-se de grande valia a utilização do princípio da precaução na saúde pública, tendo em vista que perigo de dano grave ou irreversível, bem como falta de certeza

\footnotetext{
${ }^{33}$ CUNHA, Guilherme Farias; PINTO, Cátia Carvalho; MARTINS, Sérgio; CASTILHOS JR., Armando Borges. Princípio da precaução no Brasil após a Rio-92: impacto ambiental e saúde humana. Ambiente \& Sociedade, v. 16, n. 3, p. 65-82, 2013. Disponível em: <http://www.scielo.br/pdf/asoc/v16n3/v16n3a05. pdf>. http://dx.doi.org/10.1590/S1414-753X2013000300005.

${ }^{34}$ UNESCO. World Commission on the Ethics of Scientific Knowledge and Technology (COMEST). The precautionary principle. Paris: Unesco, 2005. p. 54.

${ }^{35}$ ORGANIZAÇÃO DAS NAÇÕES UNIDAS. Declaração do Rio sobre Meio Ambiente e Desenvolvimento. Disponível em: <http://www.onu.org.br/rio20/img/2012/01/rio92.pdf>. Acesso em: 31 maio 2017.
} 
científica, são questões que possuem uma grande aproximação com os temas sanitários, envolvendo o bem-estar e a integridade de grandes populações. Nesse sentido, a precaução guarda relação com os artigos 16 e 17 da DUBDH:

Artigo 16 - O impacto das ciências da vida sobre gerações futuras, incluindo sobre sua constituição genética, deve ser devidamente considerado.

Artigo 17 - Devida atenção deve ser dada à inter-relação de seres humanos com outras formas de vida, à importância do acesso e utilização adequada de recursos biológicos e genéticos, ao respeito pelo conhecimento tradicional e ao papel dos seres humanos na proteção do meio ambiente, da biosfera e da biodiversidade ${ }^{36}$.

\subsection{Proteção}

A proteção é definida por Schramm e Kottow ${ }^{37}$ como uma particularização do princípio da responsabilidade, pois ela é usada em circunstâncias de debilidade e de risco às comunidades, ou seja, em momentos de vulnerabilidade e suscetibilidade. Kottow ${ }^{38}$ distingue esses dois últimos conceitos, entendendo a vulnerabilidade como "atributo antropológico de todo ser humano" e a suscetibilidade, como "um dano instalado em grupos sociais e indivíduos”. Em outras palavras, o propósito da proteção é regulamentar as ações do ser humano, através da previsão das implicações positivas e da prevenção das possíveis decorrências negativas.

O referencial da proteção está intimamente ligado ao da vulnerabilidade. Nesse sentido, falar em proteção em termos de saúde é considerar que, em um dado momento, haverá um grupo social ou indivíduos em situação de fragilidade, havendo necessidade de existirem normas que possam prevenir futuros danos. Assim, a proteção está relacionada com o artigo 8 da DUBDH:

Artigo 8 - A vulnerabilidade humana deve ser levada em consideração na aplicação e no avanço do conhecimento científico, das práticas médicas e de tecnologias associadas. Indivíduos e grupos de vulnerabilidade específica devem ser protegidos e a integridade individual de cada um deve ser respeitada ${ }^{39}$.

Reforçando esse entendimento, a proteção pode ser entendida como o resguardo ou a cobertura de necessidades essenciais - saúde, educação, alimento,

\footnotetext{
${ }^{36}$ UNESCO. Declaração Universal sobre Bioética e Direitos Humanos, cit.

${ }^{37}$ SCHRAMM, Fermin Roland; KOTTOW, Miguel. op. cit., p. 949-56.

${ }^{38}$ KOTTOW, Miguel. Bioética de proteção: considerações sobre o contexto latino-americano. In: SCHRAMM, Fermin Roland; REGO, Sérgio; BRAZ, Marlene; PALÁCIOS, Marisa (Orgs.). Bioética: riscos e proteção. Rio de Janeiro, UFRJ; Fiocruz, 2005. p. 29-44.

${ }^{39}$ UNESCO. Declaração Universal sobre Bioética e Direitos Humanos, cit.
} 
vestimenta, abastecimento de água, segurança e moradia (itens indispensáveis que devem ser garantidos para todas as pessoas, que sozinhas não poderiam obtê-los) ${ }^{40}$.

A proteção também pode funcionar como uma ferramenta de reflexão sobre a moralidade das práticas em saúde pública, que envolvem populações de pessoas suscetíveis e vulneradas, e que implicam problemas de justiça em situações de escassez de recursos ${ }^{41}$. Esse entendimento é crucial para a vigilância sanitária, visto que é ela uma das principais ferramentas para a aplicação das supracitadas práticas em saúde pública. De outro modo, uma vigilância sanitária pautada pela proteção garante o devido controle das novidades relacionadas com medicamentos e outros produtos que impactam a saúde.

Enfim, a proteção é o instrumento mais importante para ponderar eticamente as políticas públicas em saúde - traduzidas em condutas de vigilância sanitária -, propendendo pela justiça social. Entre outras, a proteção pode ser levada em consideração nas seguintes situações: constatação de objetivos sanitários imprescindíveis e imperiosos; presença de providências mandatórias e plausíveis com alta possibilidade de prevenção das dificuldades sanitárias através de programas de saúde; e verificação de necessidade social para o desenvolvimento da proteção, o que explica a não ingerência dos resultados negativos na legitimação do programa ${ }^{42}$.

\subsection{Prevenção}

Finalmente, a prevenção é considerada como aquela ação que se adianta às probabilidades de lesões à saúde através da procura de atos antecipados. Segundo Berlinguer ${ }^{43}$, porém, para que essa circunstância seja atingida, é necessário ter informações e certezas científicas sobre as decorrências das ações, dos processos ou dos resultados. Segundo esse renomado sanitarista e bioeticista italiano, além da "virtude antecipatória", a prevenção também tem como incentivos morais: um estilo igualitário, uma vez que quando é exercida abole a diferença entre um indivíduo afetado por uma enfermidade e outro indivíduo que não está acometido por doença nenhuma; e uma diminuição de conflitos entre interesses e, inclusive, entre valores pessoais não facilmente harmonizáveis entre si.

\footnotetext{
${ }^{40}$ PONTES, Carlos Antônio; SCHRAMM, Fermin Roland. Bioética da proteção e papel do Estado: problemas morais no acesso desigual à água potável. Cad. Saúde Pública, v. 20, n. 5, p. 1322 -1323, jan./out. 2004. Disponível em: <http://www.scielo.br/pdf/csp/v20n5/26.pdf>. http://dx.doi.org/10.1590/S0102-311X200400050002.

${ }^{41}$ SCHRAMM, Fermin Roland. É pertinente e justificado falar em bioética de proteção? In: PORTO, Dora; GARRAFA, Volnei; MARTINS, Gerson Zafalon; BARBOSA, Swedenberger do Nascimento. Bioéticas, poderes e injustiças 10 anos depois. Brasília: CFM; Cátedra Unesco de Bioética; SBB, 2012. p. 132-142.

${ }^{42}$ SCHRAMM, Fermin Roland. A moralidade da biotecnociência: a Bioética da proteção pode dar conta do impacto real e potencial das biotecnologias sobre a vida e/ou a qualidade de vida das pessoas humanas? In: SCHRAMM, Fermin Roland; REGO, Sérgio; BRAZ, Marlene; PALÁCIOS, Marisa (Orgs.). Bioética: riscos e proteção. Rio de Janeiro: Ed. UFRJ, 2005. p. 15-28.

${ }^{43}$ BERLINGUER, Giovanni. Bioética da prevenção. Revista Bioética, v. 2, n. 2, p. 1-4, 1994. Disponível em: <http://revistabioetica.cfm.org.br/index.php/revista_bioetica/article/view/457>.
} 
Pode-se dizer que a prevenção impede que ocorram danos, caracterizando-se pela adoção de cautela antes da efetiva execução de atividades potencialmente danosas. Aplica-se o referencial da prevenção nas hipóteses em que os riscos são conhecidos e previsíveis, de modo a exigir do responsável a adoção de providências visando a, se não eliminar, minimizar os danos causados. Nesse sentido, a prevenção conversaria com o artigo 4 da DUBDH da Unesco.

Especificamente na área da saúde, a prevenção é composta por medidas destinadas não apenas a prevenir a aparição de doenças - tais como a redução de fatores de risco -, mas também a deter seu avanço e atenuar suas consequências ${ }^{44}$. No campo da promoção da saúde pública, a prevenção é apenas uma parte de um amplo processo que significa a adoção de medidas gerais, de cunho educativo, com a intenção de melhorar a resistência e o bem-estar geral dos indivíduos (comportamentos alimentares, exercício físico e repouso, contenção de estresse, não ingestão de drogas ou de tabaco, entre outras), para que adquiram uma melhor resistência frente às agressões dos agentes ${ }^{45}$.

Assim, verifica-se que agir preventivamente gera benefícios palpáveis no campo da vigilância sanitária: o primeiro está na virtude antecipatória, na capacidade de intervir com a finalidade de evitar um dano; o segundo se relaciona com a questão da universalidade, em que a prevenção tem um potencial igualitário extraordinário (por exemplo, as medidas de saneamento urbano e as campanhas de vacinação que, quando implementadas, alcançam as diferentes classes sociais e surtem efeito em todas as nações do mundo); e o terceiro é relativo à capacidade de atenuar os conflitos, caso em que a vigilância é essencial ao criar ações específicas e concretas de prevenção.

\section{Considerações finais}

As práticas regulatórias no campo da vigilância sanitária constituem hoje uma realidade irreversível da qual as nações respeitosas da cidadania não podem prescindir. Por sua vez, a bioética - território relativamente novo do conhecimento científico - apresenta e disponibiliza aos profissionais, organismos públicos e países democráticos uma série de ferramentas teóricas no campo da filosofia moral para o bom exercício de suas complexas atividades.

$\mathrm{Na}$ presente reflexão, foram utilizadas duas referências para o desenvolvimento de uma análise comparativa e de apoio às atividades regulatórias no campo da vigilância sanitária. A primeira delas foi a DUBDH da Unesco, que, por meio dos artigos 4 (Benefício e Dano) e 20 (Avaliação e Gerenciamento de Riscos), propõe ferramentas interessantes para a vigilância sanitária.

\footnotetext{
${ }^{44}$ ORGANIZACIÓN MUNDIAL DE LA SALUD. Glosario de la promoción de la salud. Ginebra: Organización Mundial de la Salud, 1998.

${ }^{45}$ ORGANIZACIÓN MUNDIAL DE LASALUD. Carta de Ottawa sobre promoción de la salud. Ginebra: Organización Mundial de la Salud, 1986.
} 
$\mathrm{O}$ artigo 4, por exemplo, faz uma inovadora leitura dialética do benefício e do dano que tem um grande impacto nos debates éticos que os profissionais da vigilância sanitária devem enfrentar, uma vez que permite avaliar cuidadosamente as atuais tecnologias e produtos, cujos perigos e riscos não são totalmente conhecidos.

Já o artigo 20, com sua noção de gerenciamento do risco, complementa o artigo 4 , apresentando à área da vigilância sanitária não apenas a leitura dialética do benefício e do dano, como também a possibilidade ética de gerenciar os riscos associados àqueles possíveis danos. Isso é importante, pois dá aos professionais dessa área de conhecimento instrumentos para que tomem decisões melhores e mais justificadas.

Em segundo lugar, foi proposta a utilização da Bioética de Intervenção - e, com ela, seus "Quatro Pês" indispensáveis ao exercício de ações éticas com vistas ao bem-estar coletivo - como elemento concreto de diálogo com as ações regulatórias exigidas dos organismos públicos de vigilância sanitária, como é o caso da Anvisa no Brasil.

A proposição da prudência, da precaução, da proteção e da prevenção como princípios para que os profissionais da área de vigilância sanitária possam emitir juízos mais informados é central, levando em consideração que aportam elementos epistemológicos importantes para uma tomada de decisão mais sólida e informada. No caso da prudência e da precaução, elas permitem que esses professionais compreendam a necessidade de que suas decisões sejam baseadas em conhecimento suficiente, assim como no impacto universal que suas determinações têm.

No caso da proteção e da prevenção, elas permitem que os profissionais de vigilância sanitária deparem com conceitos tão importantes como vulnerabilidade humana e interesses econômicos, sociais e políticos. Sua importância radica-se ainda na contextualização que possibilitam. Falar em proteção e prevenção não só faz possível entender quão vulnerável é o ser humano, mas também ter ciência de que essa vulnerabilidade está condicionada por variáveis financeiras, comunitárias e relativas ao poder.

São essas algumas das razões pelas quais se considera que a bioética, nesta altura do século XXI, pode oferecer subsídios teóricos e aplicados para o exercício profissional dos organismos e técnicos que trabalham com atividades de regulação. A constatação disso pode ser avaliada pela proximidade existente entre os princípios e referenciais relacionados no presente estudo, a partir dos fundamentos epistemológicos da DUBDH da Unesco e da bioética de intervenção.

\section{Referências}

ABRAHAM, John; LEWIS, Graham. Citizenship, medical expertise and the capitalist regulatory state in Europe. Sociol., v. 36, n. 1, p. 67-88, 2002.

AGÊNCIA NACIONAL DE VIGILÂNCIA SANITÁRIA. Regulação sanitária. Disponível em: <portal.anvisa.gov.br/wps/portal/anvisa/ANVISA/regulacaosanitaria>. Acesso em: 26 set. 2013. 
ANDORNO, Roberto. The precautionary principle: a new legal standard for a technological age. Journal of International Biotechnology, v. 1, n. 1, p. 11-19, 2005. https://doi.org/10.1515/jibl.2004.1.1.11.

AQUINO, Tomás. Suma teológica $V$ - A fé. A esperança. A caridade. A prudência. II Seção da II Parte, Questões 1-56. São Paulo: Edições Loyola; 2004.

BARRETO, Mauricio. O conhecimento científico e tecnológico como evidência para políticas e atividades regulatórias em saúde. In: COSTA, Edina Alves (Org.). Vigilância sanitária: desvendando o enigma. Salvador: Edufba. 2008. p. 91-106.

BEAUCHAMP, Tom; CHILDRESS James. Principles of biomedical ethics. $1^{\text {st }}$. ed. New York; Oxford: Oxford University Press, 1979.

$\overline{\text { University Press, } 2013 .}$. Principle.

BELLINO, Francesco. Fundamentos de bioética: aspectos antropológicos, ontológicos e morais. Bauru: EDUSC, 1991.

BERLINGUER, Giovanni. Bioética da prevenção. Revista Bioética, v. 2, n. 2, p. 1-4, 1994.

Disponível em: <http://revistabioetica.cfm.org.br/index.php/revista_bioetica/article/view/457>.

BOFF, Leonardo. Saber cuidar: ética do humano - compaixão pela terra. 6. ed. Petrópolis: Vozes, 2000.

BRASIL. Código Penal brasileiro. São Paulo: Saraiva, 2002.

BUFLER, Patricia; KYLE, Amy. Regulatory reform proposals and public health. Environ. Health Perspect, v. 104, n. 4, p. 356-361, 1996. Disponível em: <https://www.ncbi.nlm.nih. gov/pmc/articles/PMC1469327/>.

CUNHA, Guilherme Farias; PINTO, Cátia Carvalho; MARTINS, Sérgio; CASTILHOS JR., Armando Borges. Princípio da precaução no Brasil após a Rio-92: impacto ambiental e saúde humana. Ambiente \& Sociedade, v. 16, n. 3, p. 65-82, 2013. Disponível em: <http://www.scielo. br/pdf/asoc/v16n3/v16n3a05.pdf>. http://dx.doi.org/10.1590/S1414-753X2013000300005.

GARRAFA, Volnei. Ampliação e politização do conceito internacional de bioética. Revista Bioética, v. 20, n. 1, p. 9-20, 2012. Disponível em: <http://revistabioetica.cfm.org.br/index. php/revista_bioetica/article/view/711/731>.

. Bioética e manipulação da vida. In: NOVAES, Adauto (Org.). O homem-máquina - a ciência manipula o corpo. São Paulo: Companhia das Letras. 2003. p. 213-225.

. De uma bioética de princípios a uma bioética interventiva. Revista Bioética CFM, v. 13, n. 1, p. 125-134, 2005. Disponível em: <http://revistabioetica.cfm.org.br/index.php/ revista_bioetica/article/view/97/102>. 
GARRAFA, Volnei. O novo conceito de bioética. In: GARRAFA, Volnei; KOTTOW, Miguel; SAADA, Alya (Orgs.). Bases conceituais da bioética: enfoque latino-americano. São Paulo: Ed. Global; UNESCO. 2006. p. 9-15.

. Transgênicos, ética e controle social. O Mundo da Saúde, v. 23, n. 5, p. 286-289, 1999.

; PORTO, Dora. Intervention bioethics: a proposal for peripheral countries in a context of power and injustice. Bioethics, v. 17, n. 5-6, p. 399-416, 2003. 10.1111/1467-8519.00356.

GRACIÁN, Baltasar. A arte da prudência. São Paulo: Martin Claret, 2006.

HEIDEGGER, Martin. Being-in-the world as being-with and being a self: the they. In: HEIDEGGER, Martin. Being and time. Translated Joan Stambaugh. New York: State University of New York Press. 1996. p. 107-122. (SUNY series in contemporary continental philosophy).

KANT, Immanuel. Fundamentação da metafísica dos costumes. Tradução Paulo Quintela. Lisboa: Edições 70, 1997.

KOTTOW, Miguel. Bioética de proteção: considerações sobre o contexto latino-americano. In: SCHRAMM, Fermin Roland; REGO, Sérgio; BRAZ, Marlene; PALÁCIOS, Marisa (Orgs.). Bioética: riscos e proteção. Rio de Janeiro, UFRJ; Fiocruz, 2005. p. 29-44.

LEITE, Denise Ferreira; BARBOSA, Patrícia Fernanda Toledo; GARRAFA, Volnei. Autohemoterapia, intervenção do Estado e Bioética. Rev Assoc Médica Brasileira, v. 54, n. 2, p. 183-188, mar./abr. 2008. Disponível em: <http://www.scielo.br/pdf/ramb/v54n2/a26v54n2.pdf>. http://dx.doi.org/10.1590/S0104-42302008000200026.

LÉVINAS, Emmanuel. Éthique et infini. Fayar France Culture. 1984.

MARQUES, Ramiro. A prudência em Aristóteles. Disponível em: <http://www. eses.pt/usr/ramiro/docs/etica_pedagogia/a\%20prud\%C3\%AAncia\%20em\%20 arist\%C3\%B3teles\%5B1\%5D.pdf>. Acesso em: 22 jun. 2016.

MORI, Maurizio. A bioética: sua natureza e história. Humanidades (UnB), Brasília, v. 9, n. 4, p. 332-341, 1994.

NASCIMENTO Wanderson Flor, GARRAFA, Volnei. Por uma vida não colonizada: diálogo entre Bioética de Intervenção e Colonialidade. Saúde Soc São Paulo, v. 20, n. 2, p. 287-299, 2011. Disponível em: <http://www.revistas.usp.br/sausoc/article/view/29791/31673>.

ORGANIZACIÓN MUNDIAL DE LA SALUD. Carta de Ottawa sobre promoción de la salud. Ginebra: Organización Mundial de la Salud, 1986.

. Glosario de la promoción de la salud. Ginebra: Organización Mundial de la Salud, 1998.

PARANHOS, Flávio Rocha Lima; MELO, Rosana Leite; GARRAFA, Volnei. Estudo crítico do Princípio de Benefício e Dano. Revista Bioética, v. 23, n. 1, p. 12-19, 2015. Disponível em: <http://www.scielo.br/pdf/bioet/v23n1/1983-8034-bioet-23-1-0012.pdf>. 
PONTES, Carlos Antônio; SCHRAMM, Fermin Roland. Bioética da proteção e papel do Estado: problemas morais no acesso desigual à água potável. Cad. Saúde Pública, v. 20, n. 5, p. 1322 -1323, jan./out. 2004. Disponível em: <http://www.scielo.br/pdf/csp/v20n5/26. pdf>. http://dx.doi.org/10.1590/S0102-311X200400050002.

POTTER, Van Rensselaer. Bioethics: a bridge to the future. New Jersey: Prentice-Hall, 1971.

. Bioethics, the science of survival. Perspectives in Biology and Medicine, New York, v. 14 , p. $127-153,1970$.

REICH, Warren Thomas. Encyclopedia of Bioethics. $2^{\text {nd }}$ ed. New York: Macmillan Press; 1995.

SCHRAMM, Fermin Roland. A moralidade da biotecnociência: a Bioética da proteção pode dar conta do impacto real e potencial das biotecnologias sobre a vida e/ou a qualidade de vida das pessoas humanas? In: SCHRAMM, Fermin Roland; REGO, Sérgio; BRAZ, Marlene; PALÁCIOS, Marisa (Orgs.). Bioética: riscos e proteção. Rio de Janeiro: Ed. UFRJ, 2005. p. 15-28.

.É pertinente e justificado falar em bioética de proteção? In: PORTO, Dora; GARRAFA, Volnei; MARTINS, Gerson Zafalon; BARBOSA, Swedenberger do Nascimento. Bioéticas, poderes e injustiças 10 anos depois. Brasília: CFM; Cátedra Unesco de Bioética; SBB, 2012. p. 132-142.

; KOTTOW, Miguel. Principios bioéticos en salud pública: limitaciones y propuestas. Cad. Saúde Pública, v. 17, p. 949-956, 2001. Disponível em: <http://www.scielo. br/pdf/csp/v17n4/5301.pdf>. http://dx.doi.org/10.1590/S0102-311X2001000400029.

. World Commission on the Ethics of Scientific Knowledge and Technology (COMEST). The precautionary principle. Paris: Unesco, 2005.

UNITED STATES OF AMERICA. Department of Health, Education, and Welfare. Belmont Report. Disponível em: <http://www.hhs.gov/ohrp/humansubjects/guidance/belmont. html>. Acesso em: 22 nov. 2013.

Volnei Garrafa - Pós-Doutor em Bioética pela Universidade La Sapienza (Roma, Itália). Coordenador do Programa de Pós-Ggraduação em Bioética/Cátedra Unesco de Bioética da Universidade de Brasília. Brasília/DF, Brasil. E-mail: garrafavolnei@gmail.com.

Karla Amorim - Pós-Doutora em Bioética do Programa de Pós-Graduação em Bioética/ Cátedra Unesco de Bioética da Universidade de Brasília. Professora na área de Bioética na Universidade Federal do Rio Grande do Norte. Natal/RN, Brasil.

Ticiana Garcia - Mestranda em Bioética do Programa de Pós-Graduação em Bioética/Cátedra Unesco de Bioética da Universidade de Brasília. Brasília/DF, Brasil.

Camilo Manchola - Doutorando em Bioética do Programa de Pós-Graduação em Bioética/ Cátedra Unesco de Bioética da Universidade de Brasília. Brasília/DF, Brasil. 